\title{
Hubungan Pre-Eklampsia Dengan Angka Kejadian Seksio Sesaria
}

\author{
Andi Syintha Ida ${ }^{1}$, Nurjaya ${ }^{2}$, Andi Ika Abriani ${ }^{3}$ \\ 1,2 Jurusan Kebidanan Poltekkes Kemenkes Makassar, \\ ${ }^{3}$ RSUP Dr.Wahidin Sudirohusodo, \\ Email : syntaIda@poltekkes-mks.ac.id; nurjaya@poltekkes-mks.ac.id; ikaabriani@gmail.com
}

\begin{abstract}
ABSTRAK
Latar belakang: Pre-eklampsia merupakan salah satu faktor penyebab tingginya angka kematian ibu dan bayi terutama di negara berkembang seperti Indonesia dan ini akan terus meningkat apabila usaha untuk mencegah tidak secara berkualitas dan professional, salah satu penanganan pre-eklampsia adalah tindakan Seksio sesaria yang bagi tenaga medis merupakan pilihan utama untuk menyelamatkan ibu dan janin, sebab penundaan persalinan yang lebih lama akan menimbulkan bahaya yang serius bagi ibu, janin atau keduanya.

Tujuan : diketahuinya hubungan Pre-eklampsia dengan angka kejadian seksio sesaria

Metode : Desain penelitian observasi analitik dengan pendekatan cross sectional. Tehnik Pengambilan sampel adalah accidental sampling dengan jumlah sample sebanyak 40 responden.

Hasil : menunjukkan dari 40 responden terdapat 35 (87,5\%) yang mengalami pre-eklampsia dan 5 $(12,5 \%)$ yang mengalami pre-eklampsia berat. dilakukan seksio sesaria $25(62,5 \%)$ yang dan 15 $(37,5 \%)$ tidak dilakukan seksio sesaria. Berdasarkan hasil uji statistik di dapatkan nilai $p=0,005<\alpha=$ 0,05. Simpulan ada hubungan signifikan antara kejadian Pre-eklampsia dengan angka kejadian seksio sesaria di RSUP.Dr.Wahidin Sudirohusodo Makassar pada tahun 2018
\end{abstract}

Kata Kunci : pre-eklampsia , Seksio sesaria

\section{ABSTRACT}

Background: Pre-eclampsia is one of the factors causing high maternal and infant mortality rates, especially in developing countries such as Indonesia and this will continue to increase if efforts to prevent not being qualified and professional, one of the treatments of pre-eclampsia is the act of Cesarean section

which for medical personnel is the main choice to save the mother and fetus, because longer delays in delivery will cause serious harm to the mother, fetus or.

Purpose: toknow the relationship of Pre-eclampsia with the number of incidents Cesarean section

Method: Design analytical observational research with a cross sectional approach. Sampling technique is accidental sampling with the number of samples as many as 40 .

The results showed that of 40 respondents there were 35 (87.5\%) who had pre-eclampsia and $5(12.5 \%)$ who had severe pre-eclampsia. Based on the results of the statistical test, the value $p=0.005<\alpha=0.05$. There is a significant relationship between the incidence of Pre-eclampsia and the incidence of Cesarean section in RSUP Dr.Wahidin Sudirohusodo Makassar in 2018

Keywords: Pre-eclampsia Relationship, Cesarean section

\section{PENDAHULUAN}

Kehamilan merupakan proses alamiah dan fisiologis yang di alami oleh seorang wanita. Sebagian besar kaum wanita

menganggap bahwa kehamilan adalah peristiwa kodrati yang akan di alami oleh seluruh wanita untuk mendapatkan keturunan. ${ }^{(1)}$ Pada 
umumnya kehamilan berkembang dengan normal dan menghasilkan kehamilan sesuai dengan yang diharapkan, namun setiap kehamilan perlu perhatian khusus, untuk mencegah dan mengetahui komplikasi yang akan di temui pada kehamilan dan persalinan, baik penyakit yang di derita ibu maupun komplikasi yang ada dalam kehamilan.

Pada tahun 2015 sekitar 830 wanita meninggal Di seluruh dunia, setiap harinya karena komplikasi selama kehamilan dan persalinan. Angka Kematian Ibu di indonesia menurut World Health Statistiks tahun 2017 sebesar 126 kematian per 100.000 kelahiran hidup, sedangkan dinegara berkembang 14 kali lebih tinggi bila dibandingkan negara maju, yaitu 230 per 100.000 kelahiran, kematian ibu di dunia disebabkan pre-eklampsia 28\%, perdarahan $27 \%$, eklampsia $14 \%$, aborsi tidak aman $8 \%$, infeksi $11 \%$, penyulit persalinan $9 \%$, dan emboli 14\%. Oleh karna itu dalam Sustainable Development Goals (SDGs) Goals yang ke 3 hal yang ingin dicapai adalah Mengurangi rasio kematian ibu secara global dari 216 per 100.000 kelahiran hidup menjadi 70 per 100.000 kelahiran hidup hingga tahun 2030. (3)

Pre-eklampsia merupakan masalah kedokteran yang serius dan memiliki tingkat kompleksitas yang tinggi. Besarnya masalah ini bukan hanya karena pre-eklampsia berdampak pada ibu saat hamil dan melahirkan, namun juga menimbulkan masalah pasca persalinan akibat disfungsi endotel di berbagai organ, seperti risiko penyakit kardiometabolik dan komplikasi lainnya.(4)

Angka kematian ibu di Indonesia tergolong tinggi jika dibandingkan dengan Negara-negara ASEAN (Association of Southeast Asian Nations) lainnya. Tampak pada tahun 2015 Angka Kematian Ibu di Indonesia 126/100.000 kelahiran hidup, Malaysia 40/100.000 kelahiran hidup, Vietnam 54/100.000 kelahiran hidup, Singapore 10/100.000 kelahiran hidup, Fhilipina 114/100.000 kelahiran hidup, Thailand
20/100.000 kelahiran hidup. ${ }^{(3)}$

Profil kesehatan provinsi Sulawesi selatan tahun 2016 didapat Angka Kematian Ibu (AKI) 153 jiwa atau 103 per 100.000 kelahiran hidup (KH). Sementara data Dinas Kesehatan Kota Makassar, Angka Kematian Ibu mengalami fluktuasi selama 3 tahun terakhir yaitu Tahun 2014 sebanyak 5 kematian ibu dari 24.590 kelahiran hidup (AKI: 20,33/100.000 $\mathrm{KH}$ ), pada 2015 sebanyak 5 kematian ibu dari 25.181 kelahiran hidup AKI :19,86/100.000 KH) dan tahun 2016 sebanyak 6 kematian ibu dari 25.614 kelahiran hidup AKI : 23.42/100.000 KH dimana penyebab kematian ibu tahun 2016 yaitu 1 kasus karena perdarahan, 3 kasus karena pre-eklampsia, 1 kasus karena Solutio Plasenta, dan 1 kasus kematian ibu karena komplikasi postpartum ginjal. ${ }^{(5)}$

RSUP Dr. Wahidin Sudirohusodo merupakan rumah sakit pusat rujukan seindonesia timur yang ada di makassar,dimana data laporan dari rekam mediknya pada tahun 2017 sebanyak 125 (17 \%) ibu hamil yang mengalami pre-eklampsia dari 734 kehamilan dan seksio sesaria akibat pre-eklampsia sebanyak 74 (13,34\%) dari 405 tindakan seksio sesaria (6) (7) Tujuan Penelitian ini diketahuinya hubungan Pre-eklampsia dengan angka kejadian seksio sesaria di RSUP.Dr.Wahidin sudirohusodo Makassar Tahun 2018.

\section{METODE}

Desain penelitian yang digunakan oleh peneliti menggunakan jenis penelitian observasi analitik yaitu suatu penelitian yang bertujuan untuk mendapatkan informasi mengenai hubungan kasus Preeklampsia dengan angka kejadian Sectio Caesarea di instalasi gawat darurat Obgyn RSUP Dr.Wahidin Sudirohusodo Makassar, Pendekatan penelitian yang digunakan pada penelitian ini adalah cross sectional. (8)

Penelitan ini dilakukan di RSUP Dr, 
Wahidin Sudirohusodo Makassar pada bulan September sampai November 2018. Populasi dalam penelitian ini adalah seluruh ibu yang menderita pre-eklampsia RSUP Dr.Wahidin Sudirohusodo Makassar mulai dari September sampai November tahun 2018. Pengambilan sampel dalam penelitian ini secara accidental sampling. ${ }^{(9)}$

Data dalam penelitian ini diolah menggunakan sistem komputerisasi melalui tahap-tahap : editing, koding, entry data, cleaning data. Analisis data yang diperoleh dan di olah kemudian akan dianalisis sebagai berikut: Analisis univariat: Analisa data yang telah dikumpulkan secara kuantitatif dianalisis secara univariat untuk mengetahui distribusi frekuensi kejadian Preeklampsia berat dengan angka kejadian seksio sesaria. Analisis bivariate: Untuk mengetahui hubungan antara variabel independent (Pre-eklampsia) dengan variabel dependent (seksio sesaria) menggunakan uji statistik Chi-Square $\left(\mathrm{X}^{2}\right)$ dilakukan dengan program komputerisasi dengan tingkat kemaknaan $\mathrm{P}=0,05$

\section{HASIL}

\section{a) Analisis Univariat}

Karateristik responden pada penelitian ini berdasarkan kejadian preeklampsia dibagi menjadi preeklampsia dan preeklampsia berat dan karateristik kejadian seksio sesaria dibagi menjadi persalinan normal dan seksio sesaria.

Tabel 1 : Distribusi responden berdasarkan kejadian Pre-eklampsia

\begin{tabular}{llcr}
\hline No & Kejadian Pre-eklampsia & Frekwensi & Presentase (\%) \\
\hline 1 & Pre eklamsia & 35 & $87,5 \%$ \\
2 & Pre- eklamsia berat & 5 & $12,5 \%$ \\
\hline
\end{tabular}

Sumber : Data Primer 2018

Hasil penelitian menurut table 1 eklampsia lebih banyak dari yang mengalami menunjukkan responden yang mengalami prepre-eklampsia berat.

Tabel 2: Distribusi responden berdasar kejadian Seksio sesaria.

\begin{tabular}{llcc}
\hline No & Preeklampsia - Preeklampsia Berat & f & $\%$ \\
\hline 1 & Persalinan normal & 15 & $37,5 \%$ \\
2 & Seksio Sesaria & 25 & $62,5 \%$ \\
\hline
\end{tabular}

Sumber : Data Primer 2018

Berdasarkan data di atas bahwa ibu yang tidak mendapatkan tindakan Seksio sesaria atau dengan persalinan normal lebih kecil dibandingkan dengan ibu yang mendapatkan tindakan Seksio sesaria. Hal ini karena ibu yang mengalami pre-eklamsia masih dalam kondisi stabil, dengan pemberian terapi MgSo $40 \%$ / intravena ataupun pematangan paru dexametazone $6 \mathrm{mg} /$ intravena / 12jam, untuk dilahirkan secara pervaginam, Sedangkan ibu yang mengalami perburukan kondisi dimana tekanan darah semakin meningkat lalu dilanjutkan pemberian terapi pherdiphine tapi dalam waktu 6 jam tekanan darah tidak turun sehinga diputuskan untuk dilakukan tindakan Seksio sesaria, karena dalam kasus pre-eklampsia itu sendiri jika tidak ditangani secara segera akan menimbulkan kematian pada bayi maupun ibunya. Sedangkan pada ibu yang tidak mendapatkan tindakan Seksio sesaria karena ibu masih dalam kondisi stabil dan tidak ada tanda tanda perburukan bahkan sudah berada pada inpartu kala 1 maka dilanjutkan dengan persalinan normal atau pervaginam. 


\section{b) Analisis Bivariat}

Tabel 3 : Hubungan Pre-Eklampsia Dengan Angka Kejadian Seksio Sesaria

\begin{tabular}{ccccccccc}
\hline \multirow{2}{*}{$\begin{array}{c}\text { Kejadian Pre } \\
\text { Eklamsia }\end{array}$} & \multicolumn{3}{c}{ Kejadian Sectio Caesaria } & & \multirow{2}{*}{ Total } & \multirow{2}{*}{$p$} \\
\cline { 2 - 5 } & \multicolumn{2}{c}{ Ya } & \multicolumn{3}{c}{ Tidak } & & & \\
\cline { 2 - 5 } & $\mathrm{n}$ & $\%$ & $\mathrm{n}$ & $\%$ & $\mathrm{~N}$ & $\%$ & \\
\hline Pre-Eklamsia & 25 & 62,5 & 10 & 25 & 35 & 87,5 & 0,005 \\
Pre-Eklamsia Berat & 0 & 0 & 5 & 12,5 & 5 & 12,5 & \\
Jumlah & 25 & 62,5 & 15 & 37,5 & 40 & 100 & \\
\hline
\end{tabular}

Sumber: Data Primer 2018

Berdasarkan Tabel 3 menunjukkan bahwa dari 40 ibu bersalin yang Pre-eklampsia sebanyak 35 orang $(87,5 \%)$ dengan tindakan Seksio sesaria dengan nilai $\rho=0,005(\alpha)<0,05)$ yang berarti ada hubungan yang bermakna antara pre-eklampsia dengan angka kejadian Seksio sesaria di RSUP. Dr. Wahidin Sudirohusodo Makassar.

\section{PEMBAHASAN}

Pre-eklampsia dan eklampsia merupakan salah satu komplikasi kehamilan yang disebabkan langsung oleh kehamilan itu sendiri, sebab terjadinya masih belum jelas. Perlu ditekankan, syndrome pre-eklampsia dengan hipertensi, oedema dan proteinuria sering tidak diperhatikan oleh wanita bersangkutan sehingga tanpa disadari dalam waktu yang singkat, akan muncul pre-eklampsia berat bahkan eklampsia. (11)

Berdasarkan hasil penelitian dari $35 \mathrm{ibu}$ yang mengalami pre-eklamsia terdapat $62,5 \%$ dilakukan seksio sesaria dan $12,5 \%$ tidak dilakukan seksio sesaria, hal ini disebabkan karena ibu tidak memiliki indikasi untuk dilakukannya tindakan seksio sesaria sehingga masih dapat ditolong dengan persalinan pervaginam atau persalinan buatan, karena jika keadaan umum ibu telah diperbaiki, dan tidak memiliki faktor-faktor yang mengharuskan ibu dilakukan tindakan Seksio sesaria , maka pengakhiran kehamilan dapat ditolong dengan persalinan pervaginam atau induksi persalinan. (12)
Sementara peneliti menemukan 5 kasus yang mengalami pre-eklamsia berat dan semuanya tidak dilakukan seksio sesaria, berdasarkan hasil pengamatan penulis pasien yang dirawat dengan pre-eklampsia berat sudah memasuki inpartu kala 1 fase aktif yang dapat dilahirkan kurang dari 3 jam sehingga dilakukan observasi untuk dilakukan persalinan normal. (13)

Hasil penelitian ini juga sejalan dengan teori yang mengatakan bahwa tidak ada yang menganjurkan langsung dilakukan seksio sesaria untuk terminasi kehamilan pada preeklampsia berat, kecuali jika ada kontra indikasi persalinan pervaginam, diantaranya serviks masih lancip dan tertutup, dalam 24 jam persalinan tidak dapat diselesaikan, kepala janin masih tinggi, atau ada disproporsi sefalopelvik, sebaiknya dilakukan pengakhiran kehamilan dengan tindakan seksio sesaria. Tindakan seksio sesaria harus dilakukan untuk menyelamatkan nyawa ibu dan janin. sebab risiko terjadi asfiksia pada bayi baru lahir dapat disebabkan oleh berbagai faktor diantaranya adalah dari faktor persalinan dengan tindakan yaitu persalinan dengan sectio caesarea. (15)(16)

Merujuk pada hasil dari penelitian ini, diperlukan adanya upaya preventif menegakkan kemungkinan pre-eklampsia secara dini dengan meningkatkan kualitas dan kuantitas Ante Natal Care. Begitu ditegakkan diagnosis hipertensi dalam kehamilan harus diusahakan agar tidak 
terjadi pre-eklampsia, pre-eklampsia berat dan ekalmpsia atau terjadi komplikasi lainnya.

Jika pre-eklampsia berat terjadi pada kehamilan cukup bulan, maka terminasi kehamilan merupakan pengobatan yang paling baik, dan diusahakan lahir pervaginam, tetapi dapat diakhiri dengan tindakan seksio sesaria atau induksi persalinan jika terdapat faktorfaktor yang menyebabkan tindakan tersebut harus dilakukan untuk menyelamatkan nyawa ibu dan janin. Selanjutnya diperlukan adanya kerja sama yang baik antara tempat pelayanan kesehatan bagian kebidanan serta menghindari terjadinya eklampsia melalui pengobatan intensif pre-eklampsia.

\section{KESIMPULAN}

Dari hasil penelitian dapat diambil adalah : kejadian pre-eklamsia $(87,5 \%)$ dan yang mengalami pre-eklampsia berat $(12,5 \%)$. ibu yang mengalami preeklamsia dan dilakukan tindakan secsio caesaria atau $(62,5 \%)$ dan $(37,5 \%)$ tidak dilakukan seksio sesaria. Ada hubungan yang signifikan antara kejadian Preeklampsia dengan angka kejadian seksio sesaria di RSUP.Dr.Wahidin Sudirohusodo Makassar pada tahun 2018.

\section{SARAN}

diharapkan Hasil penelitian ini dapat digunakan sebagai tolak ukur bagi petugas pelayanan kesehatan mengenai gambaran kejadian Pre-eklampsia dengan angka kejadian seksio sesaria untuk dapat lebih meningkatkan mutu pelayanan kesehatan dan melakukan peningkatan upaya preventif dengan pelayanan pencegahan terjadinya resiko tinggi dan komplikasi kehamilan pada ibu hamil.

Bagi Peneliti yang akan meneliti hal-hal yang berkaitan dengan tindakan Seksio sesaria, diharapkan hasil penelitian ini dapat dijadikan data dasar dalam pengembangan penelitian selanjutnya dengan mengembangkan variabel penelitian yang lebih menarik dan menggunakan metode penelitian yang berbeda.

\section{DAFTAR PUSTAKA}

1. Wiknjosastro H, Prawiroharjo, Wiknjosastro, Prawirohardjo S, Wiknjosastro H. Ilmu Kebidanan. Jakarta: Yayasan Bina Pustaka-Sarwono Prawirohardjo; 2002.

2. Serry H. Perawatan Antenatal Care. In Jakarta: Salemba Medica; 2013.

3. Word Health Organize. Trend In Maternal Mortality 1990 to 2016. WHO. 2017.

4. Respita M. Pengaruh Usia kehamilan terhadap preeklampsia dan eklampsia. 2017.

5. Kementerian Kesehatan Republik Indonesia. Profil Kesehatan Indonesia tahun 2016. In Jakarta: Kemenkes RI; 2012.

6. Rostam M. Sinopsis Obsetri (jilid 1). In: Penerbit Buku Kodekteran. Jakarta: EGC; 2012.

7. Dinas Kesehatan Kota Makassar. Profil Kesehatan kota Makassar tahun 2016. In Dinkes Kota Makassar; 2016.

8. Setiawan A, Saryono. Metodologi Penelitian Kebidanan DIII, DIV, S1, dan S2. In Yogyakarta: Nuha Medika; 2011.

9. Sugiono. Metode Penelitian Kuantitatif dan kualitatif. In Bandung: Alfabeta; 2011.

10. Ndjun JE. Tata laksana preeklampsia berat. In Jakarta: Jurnal Kesehatan; 2017.

11. Cunningham. Obstetri Williams. In Jakarta: EGC; 2013.

12. Saifuddin Abdul Bari. Buku acuan nasional pelayanan kesehatan Maternal dan nonatal. In Jakarta: PT.Bina Pustaka Sarwono Prawihardjo; 2014.

13. Manuaba IBG. Pengantar Kuliah Obstetri. In Jakarta: EGC; 2012.

14. POGI. Pedoman Nasional pelayanan kedokteran. In Jakarta: POGI; 2016.

15. Fanny F. Sectio Caesarea sebagai Faktor Risiko Kejadian Asfiksia Neonatorum. Majority. 2015;4(8).

16. Dian Trilus Wijayanti. Hubungan Sectio Caesarea Dengan Kejadian Asfiksia Di Rumah Sakit 
Umum Daerah (RSUD) Syarifah Ambami Rato Ebu Bangkalan. J Ilm J-HESTECH. 2018;1(1):918.

17. Walyani ES. Asuhan Kebidanan pada Kehamilan. Yogyakarta: Puastakabaru Press; 2015.

18. Keman K. Patomekanisme preeklampsia tekini. In Jakarta: Universitas briwijaya Press; 2012.

19. Walyani ES. Asuhan Kebidanan Pada Kehamilan. Yogyakarta: Pustaka Baru Press; 2017. 